\title{
Effect of Poly (Sodium 4-Styrene Sulfonate) on the Morphology of Hydroxyapatite Particles
}

\author{
Nesa Esmaeilian Tari and Mohammad Mahdi Kashani Motlagh \\ Department of Chemistry, Iran University of Science and Technology, Tehran, 16846-13114, Iran \\ Correspondence should be addressed to Nesa Esmaeilian Tari, ne-esmailian@chem.iust.ac.ir
}

Received 16 March 2009; Revised 20 June 2009; Accepted 30 June 2009

Recommended by Anastasios Keramidas

\begin{abstract}
Nanorods hydroxyapatite, (HAP) $\mathrm{Ca}_{10}\left(\mathrm{PO}_{4}\right)_{6}(\mathrm{OH})_{2}$ is successfully prepared by water in oil microemulsion using, $\mathrm{CaCL}_{2}$ and $\mathrm{H}_{3} \mathrm{PO}_{4}$ (water phase), poly (sodium 4-styrene sulfonate) (PSSS) as template and cyclohexane as oil phase. The nano-structure of the product was studied by means of X-ray diffraction (XRD), Fourier transmission infrared spectrometer (FT-IR), scanning electron microscopy (SEM), and atomic force microscope (AFM). With this system, we could synthesize nano-particles of hydroxyapatite with high crystallinity and least agglomeration.
\end{abstract}

Copyright ( $\odot 2009$ N. Esmaeilian Tari and M. M. Kashani Motlagh. This is an open access article distributed under the Creative Commons Attribution License, which permits unrestricted use, distribution, and reproduction in any medium, provided the original work is properly cited.

\section{Introduction}

Hydroxyapatite (HAP) has been widely studied as an important biocompatible material because of its chemical similarity to the natural calcium phosphate mineral present in a biological hard tissue [1-4]. HAP also finds applications in fields of industrial or technological interests as catalyst in chromatography or gas sensor [5], water purification, fertilizers production, and drug carrier [6]. Properties of HAP, including bioactivity, biocompatibility, solubility, sinterability, castability, fracture toughness. and absorption can be tailored over wide ranges by controlling the particle composition, size, and morphology [7-9].

The morphology of calcium phosphate nanoparticles made by traditional methods as chemical coprecipitation [10], sol-gel [11], spray-pyrolysis [12], hydrothermal synthesis [13], emulsion processing [13], mechano-chemical method [14], and autocombustion methods [15] are needlelike, sheet-like, or spherical which are not more than $300 \mathrm{~nm}$ in length.

Microemulsions are thermodynamically stable dispersions of oil and water stabilized by a surfactant and, in many cases, also a cosurfactant. The microemulsions can be of the droplet type, either with spherical oil droplets dispersed in a continuous medium of water (oil in water microemulsions,
$\mathrm{O} / \mathrm{W}$ ) or with spherical water droplets dispersed in continuous medium of oil (water in oil microemulsions, W/O) [16].

In our work, we investigated the morphology of nanohydroxyapatite particles formed in the presence of PSSS as a crystal modifier using microemulsion method. The only phase in product as prepared was hydroxyapatite and it was well crystallized.

\section{Experimental}

HAP nanopowders were synthesized using the micelle as a template system where poly(sodium 4-styrene solfonate) $\left(\mathrm{CH}_{2} \mathrm{CH}\left(\mathrm{C}_{6} \mathrm{H}_{4} \mathrm{SO}_{3} \mathrm{Na}\right)\right.$, Aldrich $)$ was used as the template. Calcium chloride $\left(\mathrm{CaCl}_{2}\right.$, Merck) and phosphoric acid $\left(\mathrm{H}_{3} \mathrm{PO}_{4} 85 \%\right.$, Merck) were used as calcium and phosphorus sources, respectively. Cyclohexane (Merck) was used as oil phase. For preparing reverse micelle system 10\% volume of aqueous solution of $0.02 \mathrm{M}$ polymer was added to cyclohexane, after that aqueous solution of $5 \mathrm{M} \mathrm{CaCl}_{2}$ and aqueous solution of $3 \mathrm{M} \mathrm{H}_{3} \mathrm{PO}_{4}$ were added slowly to the reverse micelle, respectively. The mixture was stirring in all steps. Then the $\mathrm{pH}$ of microemulsion was adjusted at 12 by adding aqueous solution of $\mathrm{NaOH}$. The final milky suspension was kept for 12 hours at room temperature. The 


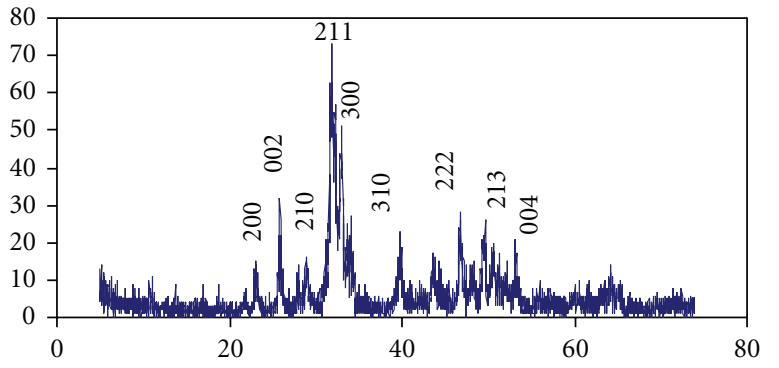

FIGURE 1: XRD pattern of HAP nanorods.

obtained precipitate was then filtered off and washed several times with deionized water. A gel-like paste was produced which was then dried at $150^{\circ} \mathrm{C}$ for 3 hours and calcined at $650^{\circ} \mathrm{C}$ for 1 hour.

The morphologies of the as-prepared HAP were observed by a scanning electron microscopy (SEM) (Cambridge-S365) equipped with energy-disperse X-ray spectroscopy and AFM (nanoscope 2). The powder X-ray diffractometer using $\mathrm{Cu}$ $\mathrm{K} \alpha$ (siemens D500) and Fourier transform infrared (FTIR) spectroscopy (shimadzu, $\mathrm{KBr}$ pellet technique) was used to identify the quality and composition of hydroxyapatite.

\section{Results and Discussion}

The wide angle $\left(2 \theta>10^{\circ}\right) \mathrm{X}$-ray diffraction patterns of the obtained sample is shown in Figure 1. The diffraction peaks correspond to the standard characteristic peaks of hexagonal HAP. There is a high consistency between the data from our sample and that from the standard database, with lattice dimensions of $a=b=0.9414 \mathrm{~nm}, c=0.6879 \mathrm{~nm}$ (space group p $6_{3} / \mathrm{m}$, JCPDS no. 09-0432). No other impurity was observed in the XRD pattern, indicating the chief inorganic phase of the sample is HAP crystal.

Figure 2 shows the FT-IR spectra of the sample. The peak at $3420 \mathrm{~cm}^{-1}$ is attributed to the $\nu_{2}$ bending mode of adsorbed water [17]. The stretching vibration band of $\mathrm{OH}^{-}$is observed at $3569 \mathrm{~cm}^{-1}$ [18]. Tow adsorption bands at 561 and $601 \mathrm{~cm}^{-1}$ are ascribed to the $\nu_{4}$ bending mode of $\mathrm{PO}_{4}^{3-}$ [19]. The characteristic band at 1024 and $1091 \mathrm{~cm}^{-1}$ are related to the stretching vibration of $\mathrm{PO}_{4}^{3-}$. The band at $951 \mathrm{~cm}^{-1}$ is assigned to $v_{1}$ stretching mode of $\mathrm{PO}_{4}^{3-}$. The typical splitting peaks at 567 and $603 \mathrm{~cm}^{-1}$ derived from the $v_{4}$ phosphate mode [19]. The FT-IR results indicate that no PSSS molecule is incorporated in the HAP.

Figure 3 shows the SEM image of the HAP nanoparticles. It reveals that the overall morphology of the obtained powders at mentioned situation is rod-like. This suggested that the presence of PSSS had greatly influenced the morphology of the product due to a strong interaction between the sulfate groups of PSSS and the $\mathrm{Ca}^{2+}$ ions in the solution and on the surface of HAP particles [20-22].

Figure 4 shows the AFM image of nanoparticles of hydroxyaopatite. AFM image confirmed that the particles of synthesized sample are rod shape. AFM image shows the resulted rod shapes HAP have an average width and length

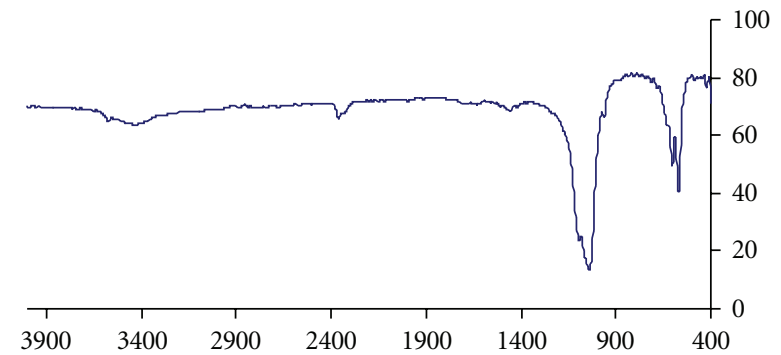

FIGURE 2: FT-IR spectra of synthesized hydroxyapatite.

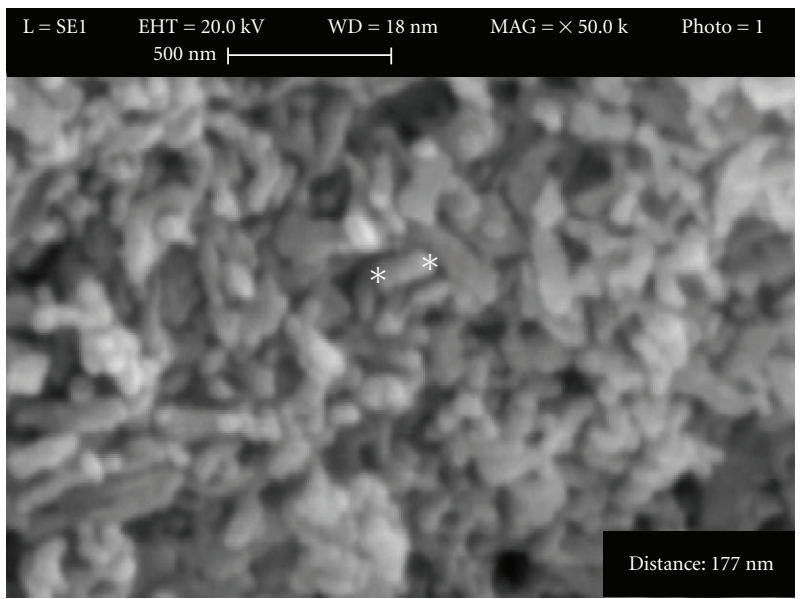

Figure 3: Scanning electron microscopy for synthesized HAP.

about 30 and $200 \mathrm{~nm}$, these sizes are adherent with SEM results which measured the width and length of the shown particle about 40 and $177 \mathrm{~nm}$ and also these dimensions evidence that the particles are rod shape.

We propose here a mechanism for the formation of HAP nanoparticles in the compositions containing the anionic polymer. Earlier studies on PSSS demonstrated that the sulfate groups are able to interact with calcium ions present in an aqueous solution. Surfactant molecules in micelles or emulsion droplet interact with $\mathrm{Ca}^{2+}$ ions to form zwitterions structures [20-22]. These numerous calcium-rich domains lead to the fast formation of HAP particles upon contact with phosphate ions in the aqueous phase. The reaction between $\mathrm{H}_{3} \mathrm{PO}_{4}$ and $\mathrm{CaCl}_{2}$ in the micelles is deemed to be rapid because of the localized $\mathrm{Ca}^{2+}$ concentration effect. In addition, the positional stabilization of $\mathrm{Ca}^{2+}$ ions within each zwitterions structure as a result of the electrostatic interaction effect by PSSS molecules favors the formation of ordered HAP crystals.

\section{Conclusion}

Drop-wise addition of $0.6 \mathrm{M} \mathrm{H}_{3} \mathrm{PO}_{4}$ solution into $1.0 \mathrm{M}$ $\mathrm{CaCl}_{2}$ solution resulted in a fast precipitation of $\mathrm{HAP}$ particles. Using PSSS as a nucleation and growth controlling agent, well-crystallized hydroxyapatite nanoparticles were precipitated via a microemulsion route. During the mixing 


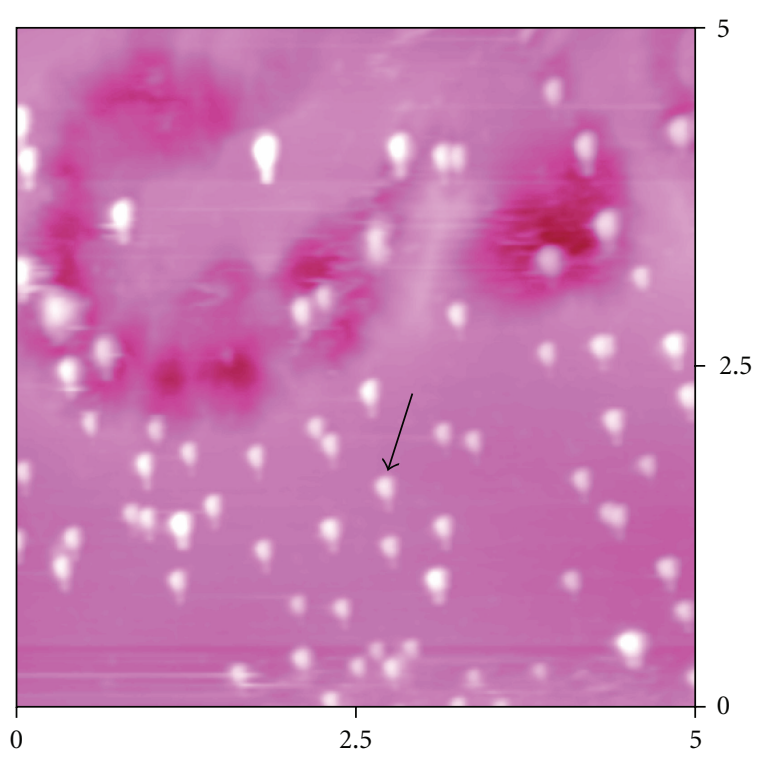

FIgURE 4: AFM image of hydroxyapatite nanoparticles.

of PSSS with calcium precursor, it formed rod-like micelles which control the morphology and crystallization of nanohydroxyapatite. X-ray diffraction pattern and FTIR spectrum of the resulted precipitates confirmed the formation of high purity and well-crystallized HAP. The SEM and AFM investigations showed that the obtained HAP nanorods have an average width and length of about 30 and $200 \mathrm{~nm}$, respectively.

\section{References}

[1] S. V. Dorozhkin and M. Epple, "Biological and medical significance of calcium phosphates," Angewandte Chemie International Edition, vol. 41, no. 17, pp. 3130-3146, 2002.

[2] G. Bezzi, G. Celotti, E. Landi, T. M. G. La Torretta, I. Sopyan, and A. Tampieri, "A novel sol-gel technique for hydroxyapatite preparation," Materials Chemistry and Physics, vol. 78, no. 3, pp. 816-824, 2003.

[3] H. Ehrlich, P. G. Koutsoukos, K. D. Demadis, and O. S. Pokrovsky, "Principles of demineralization: modern strategies for the isolation of organic frameworks-part II. Decalcification," Micron, vol. 40, no. 2, pp. 169-193, 2009.

[4] W. Suchanek and M. Yoshimura, "Processing and properties of hydroxyapatite-based biomaterials for use as hard tissue replacement implants," Journal of Materials Research, vol. 13, no. 1, pp. 94-117, 1998.

[5] J. Torrent-Burgues and R. Rodriguez-Clemente, "Hydroxyapatite precipitation in a semibatch process," vol. 36 , no. $8-10$, pp. 1075-1082.

[6] J. Arends, J. Christoffersen, M. R. Christoffersen, et al., "A calcium hydroxyapatite precipitated from an aqueous solution. An international multimethod analysis," Journal of Crystal Growth, vol. 84, no. 3, pp. 515-532, 1987.

[7] Y. Wang, S. Zhang, K. Wei, N. Zhao, J. Chen, and X. Wang, "Hydrothermal synthesis of hydroxyapatite nanopowders using cationic surfactant as a template," Materials Letters, vol. 60 , no. 12, pp. 1484-1487, 2006.
[8] H. Arami, M. Mohajerani, M. Mazloumi, R. Khalifehzadeh, A. Lak, and S. K. Sadrnezhaad, Journal of Alloys and Compounds, 2008.

[9] R. Z. Legeros, Calcium Phosphates in Oral Biology and Medicine, Karger, Basel, Switzerland, 1991.

[10] L. Yan, Y. Li, Z.-X. Deng, J. Zhuang, and X. Sun, "Surfactantassisted hydrothermal synthesis of hydroxyapatite nanorods," International Journal of Inorganic Materials, vol. 3, no. 7, pp. 633-637, 2001.

[11] P. V. Braun, P. Osenar, and S. I. Stupp, "Semiconducting superlattices templated by molecular assemblies," Nature, vol. 380, no. 6572, pp. 325-328, 1996.

[12] L. Yan, Y. Li, Z.-X. Deng, J. Zhuang, and X. Sun, "Surfactantassisted hydrothermal synthesis of hydroxyapatite nanorods," International Journal of Inorganic Materials, vol. 3, no. 7, pp. 633-637, 2001.

[13] M. H. Cao, Y. H. Wang, C. X. Guo, Y. Qi, and C. Hu, "Preparation of ultrahigh-aspect-ratio hydroxyapatite nanofibers in reverse micelles under hydrothermal conditions," Langmuir, vol. 20, no. 11, pp. 4784-4786, 2004.

[14] S. Modes and P. Lianos, "Luminescence probe study of the conditions affecting colloidal semiconductor growth in reverse micelles and water-in-oil microemulsions," Journal of Physical Chemistry, vol. 93, no. 15, pp. 5854-5859, 1989.

[15] M. L. Curri, A. Agostiano, L. Manna, et al., "Synthesis and characterization of CdS nanoclusters in a quaternary microemulsion the role of the cosurfactant," Journal of Physical Chemistry B, vol. 104, no. 35, pp. 8391-8397, 2000.

[16] R. Nagarajan and E. Ruckenstein, "Molecular theory of microemulsions," Langmuir, vol. 16, no. 16, pp. 6400-6415, 2000.

[17] M. Cao, Y. Wang, C. Guo, Y. Qi, and C. Hu, "Preparation of ultrahigh-aspect-ratio hydroxyapatite nanofibers in reverse micelles under hydrothermal conditions," Langmuir, vol. 20, no. 11, pp. 4784-4786, 2004.

[18] Y. Wang, S. Zhang, K. Wei, N. Zhao, J. Chen, and X. Wang, "Hydrothermal synthesis of hydroxyapatite nanopowders using cationic surfactant as a template," Materials Letters, vol. 60, no. 12, pp. 1484-1487, 2006.

[19] H. Wang, L. Zhai, Y. Li, and T. Shi, "Preparation of irregular mesoporous hydroxyapatite," Materials Research Bulletin, vol. 43, no. 6, pp. 1607-1614, 2008.

[20] J. Yu, H. Tang, and B. Cheng, "Influence of PSSS additive and temperature on morphology and phase structures of calcium oxalate," Journal of Colloid and Interface Science, vol. 288, no. 2, pp. 407-411, 2005.

[21] M. Lei, W. H. Tang, L. Z. Cao, P. G. Li, and J. G. Yu, "Effects of poly (sodium 4-styrene-sulfonate) on morphology of calcium carbonate particles," Journal of Crystal Growth, vol. 294, no. 2, pp. 358-366, 2006.

[22] H. Tang, J. Yu, X. Zhao, and D. H. L. Ng, "Influence of PSSS on the morphology and polymorph of calcium carbonate in the ethanol-water mixed system," Journal of Alloys and Compounds, vol. 463, no. 1-2, pp. 343-349, 2008. 


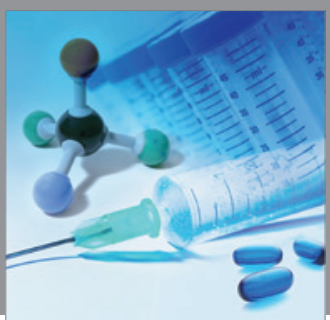

International Journal of

Medicinal Chemistry

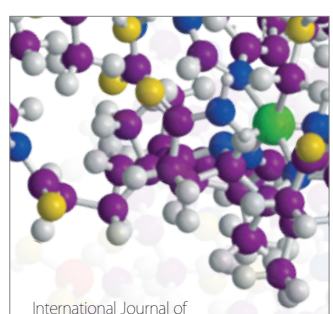

Carbohydrate Chemistry

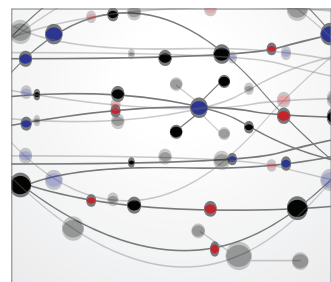

The Scientific World Journal
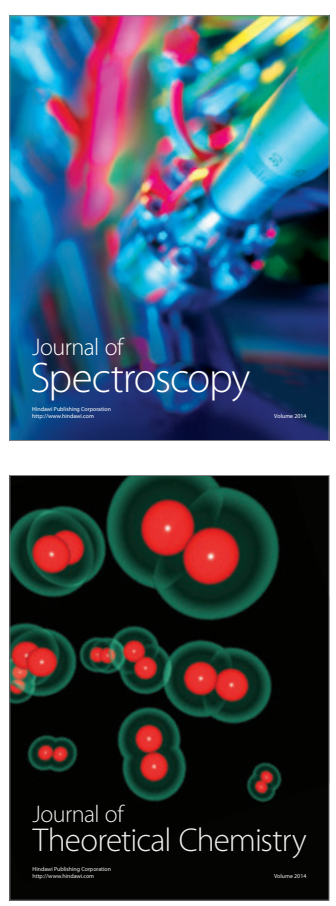
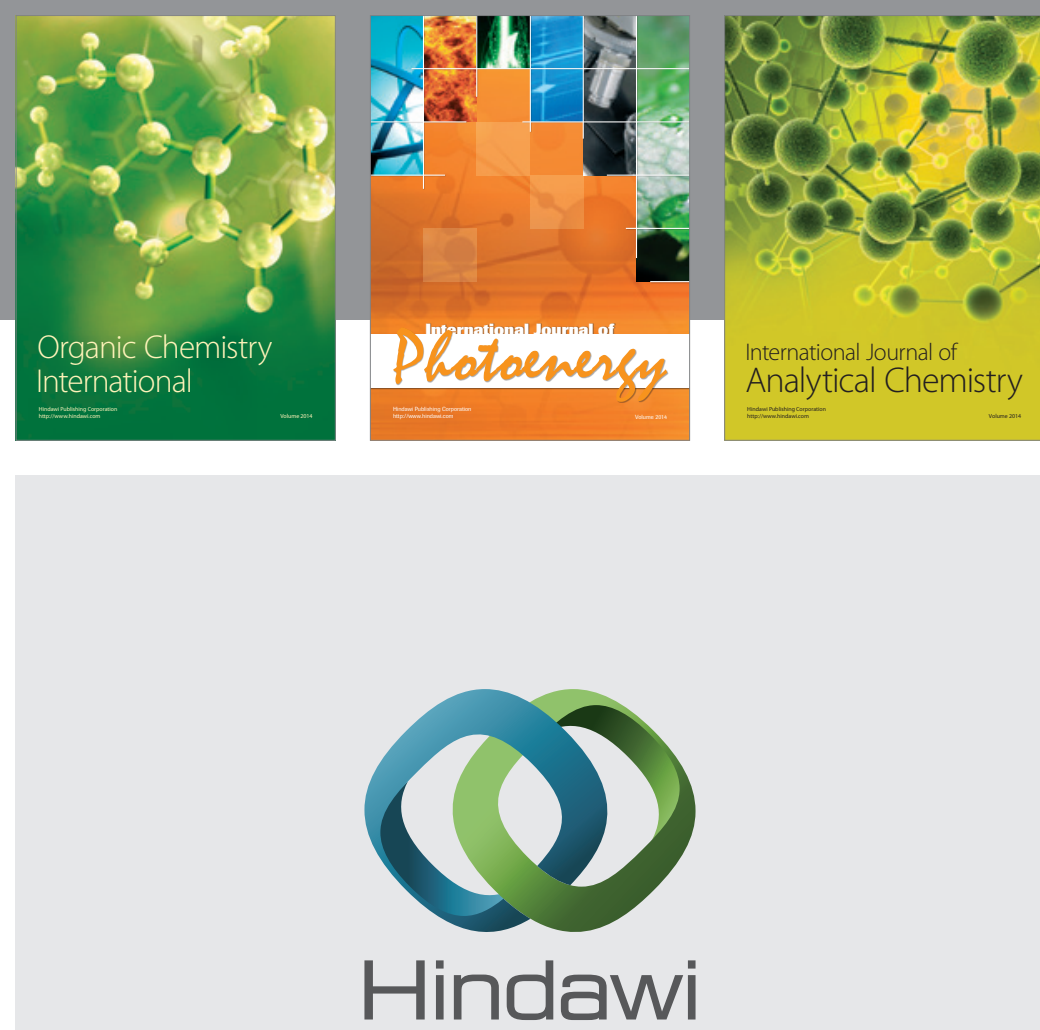

Submit your manuscripts at

http://www.hindawi.com
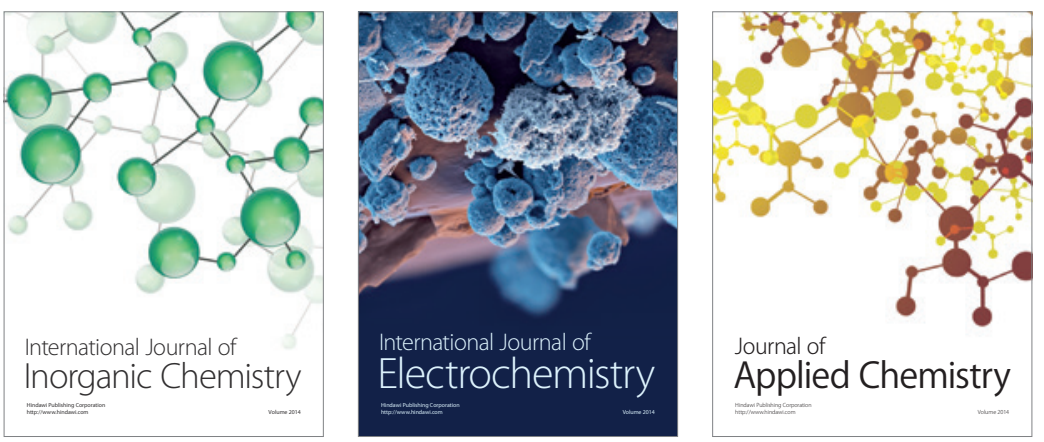

Journal of

Applied Chemistry
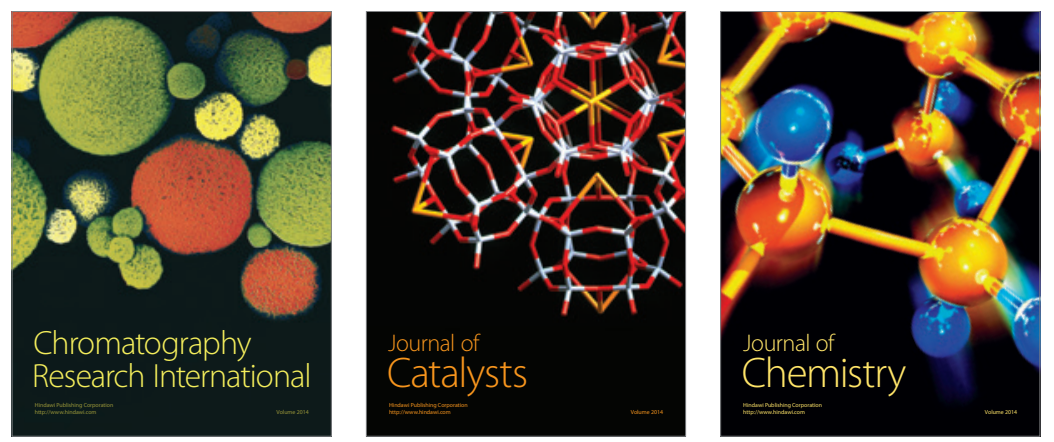
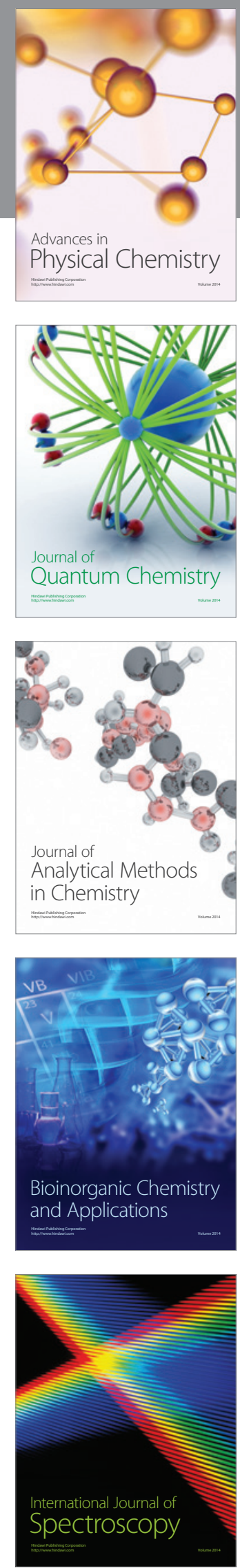